\title{
Penerapan Cobit 5 dalam Evaluasi Tata Kelola Teknologi Informasi (Studi Kasus: Dinas Perindustrian dan Perdagangan Provinsi Sumatera Utara)
}

\author{
Muhammad Dedi Irawan ${ }^{1}$, Alya Seraya ${ }^{2}$, Novita Amalia ${ }^{3}$, Reza Rizki Arifianda ${ }^{4}$ \\ ${ }^{1,2,3,4}$ Program Studi Sistem Informasi Universitas Islam Negeri Sumatera Utara \\ Jl. IAIN No 01 Medan 20235, Indonesia \\ e-mail: muhammaddediirawan@gmail.com¹, alyaseraya03@gmail.com², novamalia14@gmail.com², \\ reza.rizki@uinsu.ac.id ${ }^{4}$
}

Submitted Date: July $15^{\text {th }}, 2020$

Revised Date: October 12, 2020
Reviewed Date: July $30^{\text {th }}, 2020$

Accepted Date: October $31^{\text {st }}, 2020$

\begin{abstract}
The Department of Industri and Trade of North Sumatra Province is part of the government in the industrial and trade sector. In carrying out its operational activities, the use of information technology is used to support activities. Some problems that occur are the absence of a system for evaluating information technology governance that is used in a systematic manner. In examining the technology used, it only involves a few expert reasoning skills. The purpose of this study is to determine the extent of management and utilization of information technology in the Department of Industri and Trade of North Sumatra Province and to recommend information technology management policy proposals using COBIT version 5. The process of evaluating governance using COBIT begins with domain selection, primary and secondary data koleksi. , the mapping process, the next step is to process the questionnaire data and calculate the value and level of capability. The results of the application of COBIT 5 can explain the situation in resource optimization which includes planning, pengawasan, and adjustments to the implementation of processes and conditions that have not been met, such as making documentation regarding the management of relationships between business and information technology, making SOPs containing regulating coordination.
\end{abstract}

Kata Kunci: Evaluation of Governance; Information Technology; COBIT 5

\begin{abstract}
Abstrak
Dinas Perindustrian dan Perdagangan Provinsi Sumatera Utara merupakan bagian dari pemerintahan di bidang industri dan perdagangan. Dalam menjalankan kegiatan operasionalnya, maka digunakan pemanfaatan teknologi informasi sebagai pendukung kegiatan. Beberapa masalah yang terjadi tidak adanya sistem evaluasi tata kelola teknologi informasi yang digunakan secara tersistem. Dalam pemeriksaan teknologi yang digunakan hanya melibatkan beberapa kemapuan nalar yang pakar. Tujuan dari penelitian ini untuk mengetahui sejauh mana pengelolaan dan pemanfaatan teknologi informasi di Dinas Perindustrian dan Perdagangan Provinsi Sumatera Utara dan merekomendasikan usulan kebijakan pengelolaan teknologi informasi menggunakan COBIT versi 5. Proses evaluasi tata kelola menggunakan COBIT ini dimulai dengan pemilihan domain, pengumpulan data primer dan sekunder, proses pemetaan, selanjutkan adalah mengolah data kuesioner dan menghitung nilai dan level kapabilitas. Hasil dari penerapan COBIT 5 dapat menjelaskan keadaan pada optimasi sumber daya yang mencakup perencanaan, pengawasan dan penyesuaian pada pelaksanaan proses dan keadaan syarat yang belum terpenuhi seperti membuat dokumentasi mengenai pengelolaan hubungan antara bisnis dengan teknologi informasi, membuat SOP yang berisi mengatur koordinasi.
\end{abstract}

Kata Kunci: Evaluasi Tata Kelola; Teknologi Informasi; COBIT 5 


\section{Pendahuluan}

Teknologi saat sekarang semakin berkembang dengan pesat salah satunya pada komputer dan informasi. Perusahaan mengambil sistem informasi berbasis komputer sebagai wadah agar perusahaannya lebih berkembang dan mendapatkan kelancaran dalam kegiatan operasional perusahaan seperti pada suatu instansi. Aset teknologi informasi yaitu bagian penting pada perusahaan untuk di zaman teknologi seperti ini karena apabila tidak ada maka perusahaan sulit berjalan. Dalam menyelesaikan permasalahan tersebut pentingnya adanya evaluasi tata kelola teknologi informasi.

Dinas Perindustrian dan Perdagangan Sumatera Utara merupakan bagian dari pemerintahan di bidang industri dan perdagangan. Adapun maksud dan tujuan untuk dapat mewujudkan usaha industri dan perdagangan yang efesien, maju dan mandiri. Dinas Perindustrian dan Perdagangan Sumatera Utara memiliki pemanfaatan inovasi data yang mampu membantu aktivitas organisasi sehari-hari hanya sebagai korespondensi dengan jaringan. Hal yang terjadi saat ini adalah evaluasi digunakan dengan nalar manusia yang pakar dalam evaluasi tersebut sehingga memungkinkan ketidakselarasan antara tujuan bisnis dengan tujuan teknologi informasi.

Jika ada masalah di lebih dari satu sudut pandang yang muncul, maka penilaian selesai. Strategi yang diusulkan dalam menilai harl tersebut menggunakan COBIT 5. Metode evaluasi ini memiliki cakupan jangkauan masalah yang luas dengan terdapatnya 37 proses. Maka dari itu, peneliti menggunakan COBIT dengan versi COBIT 5 karena prosesnya lebih holistic, menyelesaikan dan menggabungkan latihan inovasi data dan bisnis dari awal hingga akhir.

Eksplorasi penilaian administrasi inovasi data telah dilakukan sebelum memanfaatkan COBIT 5, khususnya konsekuensi penilaian tergantung pada ukuran APO08.01 hingga APO08.05, dimana tingkat kemampuan insentif pada siklus APO08.01 didapatkan dengan perkembangan saat ini level di level 3, diulangi betapapun alami dengan harga diri pengembangan. 2.70(Sa'diyah \& Manuputty, 2018). Sedangkan pada investigasi yang berbeda pada asesmen pada siklus APOO08 pada level 1 dan 2 terdapat administrasi hubungan antar staf namun tidak ada SOP untuk melakukan siklus tersebut. (Basil, Agitha, \& Albar, 2019). COBIT 5 juga pernah digunakan untuk mengurangi Efektivitas COBIT 5 Kerangka Keamanan Informasi untuk mengurangi Serangan Cyber pada Sistem Manajemen Rantai Pasokan (Wolden, Valverde, \&
Talla, 2015). Untuk Menilai COBIT 5 pernah dilakukan penelitian menggunakan Menggunakan ArchiMate dan Implementasi ITIL Rafael(Almeida, Pinto, \& Da Silva, 2016). Kasus COBIT 5 pernah dikaji dengan penekanan landasan teoritis tata kelola teknologi informasi (Devos \& Van De Ginste, 2015). Tampilan pakar untuk penerapan selektif COBIT 5 pernah digunakan untuk baseline minimum dalam tata kelola teknologi informasi (Bartens, de Haes, Lamoen, Schulte, \& Voss, 2015). Pemetaan ke domain COBIT pernah digunakan dalam Komunikasi dan kontrol dalam proyek pengembangan Sistem Informasi yang dialihdayakan(Gantman \& Fedorowicz, 2016).

Rencana penelitian penerapan tata kelola teknologi informasi pemanfaatan COBIT 5 adalah untuk sampai sejauh mana pengelolaan dan pemanfaatan teknologi informasi di Dinas Perindustrian dan Perdagangan Provinsi Sumatera. Dengan adanya evaluasi tata kelola teknologi informasi ini akan membantu manajemen dalam penggunaan sumberdaya teknologi informasi dan bertambahnya pengetahuan dalam penggunaan COBIT 5 sebagai kerangka kerja untuk pengevaluasian tata kelola teknologi informasi.

\section{Metode Penelitian}

\subsection{Studi Literatur}

Pada penelitian ini melakukan studi literatur sebagai salah satu metodologi. Di mana peneliti mengamati hasil penelitian terdahulu dalam mengevaluasi tata kelola teknologi informasi menggunakan COBIT 5 seperti karya ilmiah/jurnal ilmiah. Selain itu peneliti juga melakukan pengamatan pada perusahaan berdasarkan kondisinya dan mencari informasi dari perusahaan tersebut.

\subsection{Pemilihan Domain COBIT 5}

Penetapan arsip usaha di Dinas Perindustrian dan Perdagangan Provinsi Sumatera Utara dan perbincangan dengan pertemuan-pertemuan penting dari bagian pengembang. Pilihan area COBIT tergantung pada data yang didapat dan tujuannya adalah agar siklus penilaian sesuai dengan tujuan bisnis organisasi.

\subsection{Pengumpulan Data \\ 2.3.1 Pengumpulan Data Primer dan Data Sekunder}

Peneliti mengumpulkan informasi penting secara subjektif dalam persepsi dan strategi jajak pendapat. Dalam teknik persepsi ini, peneliti melihat visi, misi dan tujuan dengan melakukan 
investigasi terhadap kondisi yang ada. Sementara itu, teknik polling dilakukan dengan menyebarkan survei ke divisi kerja yang akan dinilai yang berisi beberapa pertanyaan seputar penggunaan dan inovasi data dewan ke divisi kerja.

Dalam kumpulan informasi opsional, peneliti mengumpulkan data tentang citra keseluruhan organisasi (struktur, visi, misi, target). Dimana informasi tambahan diperoleh dari hasil investigasi laporan yang telah dilakukan selama persepsi langsung.

\subsubsection{Mapping}

Pada tahap ini peneliti diarahkan dengan perencanaan visi, misi dan sasaran Dinas Perindustrian dan Perdagangan Provinsi Sumatera Utara yang diperoleh dari tahap pengumpulan informasi opsional. Dilihat dari visi, misi dan target perencanaannya maka akan dapat dibayangkan untuk mencapai tujuan bisnis dan tujuan inovasi data yang akan dilakukan dengan memanfaatkan struktur COBIT 5 yang berpusat di sekitar APO. Siklus perencanaan mengharapkan untuk mengetahui APO mana yang berlaku yang perlu ditinjau secara lebih rinci

\subsection{Pengolahan Data}

Dalam pengolahan data digunakan framework COBIT 5, yaitu dengan menghitung capability level menggunakan skala likert dengan menghitung rekapitulasi jawaban kuesioner dan menghitung nilai serta level kapabilitas dari hasil kuesioner(Surendo, 2019).

\subsubsection{Memastikan Rekapitulasi Jawaban Kuesioner}

$$
\mathrm{C}=\frac{H}{J R} \times 100 \%
$$

\section{Keterangan:}

C : Rekapitulasi jawaban survei Capability Level

$\mathrm{H}$ : Kuantitas jawaban survei Capability Level untuk setiap pilihan jawaban level 0 sampai 5 untuk setiap tindakan

JR : Jumlah responden / aset orang

\subsubsection{Menghitung Nilai dan Tingkat Kemampuan}

$$
\mathrm{NK}=\frac{\begin{array}{l}
(L P \times N k 0)+(L P \times N k 1)+(L P \times N k 2)+ \\
(L P \times N k 3)+(L P \times N k 4)+(L P \times N k 5)
\end{array}}{100} .
$$

Keterangan :

NK : Estimasi perkembangan dalam siklus TI

LP : Tingkat persentase (tingkat tingkat pada setiap penyampaian tanggapan untuk survei Tingkat Kemampuan)

$\mathrm{Nk}$ : Harga pengembangan dicatat dalam tabel perencanaan respons yang sesuai, nilai dan tingkat pengembangan

\section{Hasil dan Pembahasan}

\subsection{Pemilihan Domain Cobit}

Pada tahap ini area dalam COBIT 5 diselesaikan. Area COBIT dipilih dengan mempertimbangkan laporan bisnis Dinas Perindustrian dan Perdagangan Provinsi Sumatera Utara dan rapat pengarahan. Berdasarkan hasil investigasi catatan bisnis dan hasil pertemuan, salah satu tujuan keseluruhan organisasi yang terdapat dalam kisi target bisnis dipilih sesuai dengan tujuan bisnis di Dinas Perindustrian dan Perdagangan Provinsi Sumatera Utara dengan tujuan keseluruhan yaitu bisnis No. 11 Optimisation of business process functionality (Optimalisasi fungsi proses bisnis)(ISACA, 2012a).

Mengingat Tujuan Perusahaan yang dipilih, ini sejalan dengan pembedaan Tujuan Terkait TI dari Dinas Perindustrian dan Perdagangan Sumatera Utara, dari kerangka hanya kebutuhan esensial yang harus dipilih. Mengenai misi Dinas Perindustrian dan Perdagangan Sumatera Utara "Memperkuat struktur modern, melibatkan potensi yang ada dan memberdayakan jaringan bisnis keuangan" maka IT-Related Goals COBIT 5 yang sesuai dengan keadaan di Dinas Perindustrian dan Perdagangan Sumatera Utara adalah Pemberdayaan dan dukungan ukuran bisnis dengan mengoordinasikan aplikasi dan inovasi data ukuran bisnis (Pemberdayaan dan dukungan tindakan bisnis dengan memasukkan aplikasi dan inovasi ke dalam ukuran bisnis)(ISACA, 2012a).

Setelah itu tahap selanjutnya adalah memilih area yang mengkoordinasikan perencanaan pada $I T$ Related Goals COBIT 5 yang menghasilkan 3 ukuran COBIT yang esensial APO08 Manage Relationship, BAI02 Manage Requirements Definition, BAI07 Manage Change Acceptance dan Transitioning Acceptance Perubahan dan Transisi(ISACA, 2012b).

Dari tiga siklus tersebut, dipilih satu siklus yang disesuaikan dengan Dinas Perindustrian dan Perdagangan Sumatera Utara. Proses Domain adalah Proses Pengelolaan Hubungan APO08, di mana APO08 adalah administrasi asosiasi bisnis yang formal dan lugas dengan TI yang menjamin 
bahwa perhatian tertuju pada pencapaian tujuan bersama dan organisasi yang efektif menghasilkan tujuan utama yang normal dan rencana pengeluaran di dalam dan batas resistensi. Dengan harapan dapat meningkatkan hasil, meningkatkan kepastian IT dan pemanfaatan aset secara memadai. APO08 Ada beberapa sub-ukuran, khususnya:

1. APO08.01 Memahami keinginan bisnis,

2. APO08.02 Identifikasi peluang, bahaya dan hambatan bagi TI untuk meningkatkan bisnis,

3. APO08.03 Mengelola Hubungan Bisnis,

4. APO08.04 Koordinasi dan Berkomunikasi,

5. APO08.05 Memberikan Masukan untuk Peningkatan Layanan Berkelanjutan

\subsection{Pengumpulan Data}

Di penelitian ini, kuesioner dilakukan untuk menilai tingkat kapabilitas TI saat ini, dengan menggunakan COBIT 5. Responden kuesioner merupakan pihak yang terkait dengan penerapan TI pada Dinas Perindustrian dan Perdagangan Provinsi Sumatera Utara adalah:

1. Sekretariat dalam Sub Bagian Program, Akuntansi dan Informasi Publik.

2. Staff dalam Sub Bagian Program.

Dari wawancara yang diperoleh dengan pihak tertentu, terdapat beberapa informasi yang berguna dalam penelitian ini, salah satunya adalah hambatan yang terjadi selama penggunaan TI di Dinas Perindustrian dan Perdagangan Provinsi Sumatera Utara yaitu:

1. Fasilitas TI yang kurang memadai membuat terhambatnya penggunaan teknologi Informasi tersebut.

2. Kemampuan SDM yang kurang memadai dalam penggunaan teknologi.

3. Terkait jaringan yang ada pada teknologi informasi di Dinas Perindustrian dan Perdagangan Provinsi Sumatera Utara.

\subsection{Pengolahan Data}

Dalam menentukan posisi di setiap level ada empat yaitu, null $(\mathrm{N})$, partially $(\mathrm{P})$, Largely Achieved (L) dan Fully Achieved (F). Siklus diucapkan telah sampai pada suatu tingkat jika peringkatnya ada di kelas L atau F. Meskipun demikian, sebuah siklus dapat dilanjutkan ke tingkat berikutnya jika posisi pada suatu tingkat baru saja mendapat peringkat $\mathrm{F}$.

\subsection{Data Validation}

Sehubungan dengan penentuan siklus COBIT yang telah digambarkan, terdapat 5 ukuran COBIT yang akan diestimasi besarnya kapasitasnya. Dimana pada siklus penilaian setiap siklus akan disurvei secara bertahap mulai dari level 1 hingga level 5.

Di tahapan ini, dilakukan perhitungan evaluasi penilaian agar mengetahui capability level yang dimiliki oleh Dinas Perindustrian dan Perdagangan Sumatera Utara. Perhitungan kuesioner ini digunakan metode Skala Likert yang terdapat pada COBIT 5. Tingkat pencapaian yang tengah berjalan pada organisasi tersebut akan dijelaskan pada tabel berikut.

Tabel 1 Hasil Rekapitulasi Jawaban Kuesioner APO08

\begin{tabular}{|l|l|l|l|l|l|l|l|l|}
\hline \multirow{2}{*}{ Proses } & \multirow{2}{*}{ Distribusi Jawaban (\%) } \\
\cline { 2 - 9 } & Aktivitas Proses & 0 & 1 & 2 & 3 & 4 & 5 \\
\hline \multirow{2}{*}{ “APO08.01" } & Kondisi Sekarang & 16 & 8 & 24 & 60 & 24 & 0 \\
\cline { 2 - 9 } & Kondisi Yang Diinginkan & 8 & 0 & 4 & 48 & 20 & 52 \\
\hline \multirow{2}{*}{ "APO08.02" } & Kondisi Sekarang & 12 & 12 & 32 & 8 & 36 & 0 \\
\cline { 2 - 9 } & Kondisi Yang Diinginkan & 4 & 8 & 0 & 20 & 28 & 40 \\
\hline \multirow{2}{*}{ "APO08.03" } & Kondisi Sekarang & 4 & 8 & 36 & 20 & 28 & 0 \\
\cline { 2 - 9 } & Kondisi Yang Diinginkan & 0 & 12 & 20 & 16 & 8 & 40 \\
\hline \multirow{2}{*}{ "APO08.04" } & Kondisi Sekarang & 12 & 4 & 24 & 20 & 20 & 0 \\
\cline { 2 - 9 } & Kondisi Yang Diinginkan & 8 & 4 & 8 & 16 & 4 & 40 \\
\hline \multirow{2}{*}{ "APO08.05" } & Kondisi Sekarang & 4 & 8 & 20 & 16 & 12 & 0 \\
\cline { 2 - 9 } & Kondisi Yang Diinginkan & 0 & 8 & 0 & 16 & 8 & 24 \\
\hline
\end{tabular}

Berdasarkan hasil rekapitulasi keseluruhan Jawaban responden di atas, sangat mungkin disimpulkan bahwa sebagian besar responden mengisi kuesioner pada aktivitas proses Kondisi Sekarang (as is) yaitu terdapat ditingkat kapabilitas
2. Sedangkan pada Kondisi Yang Diinginkan (to be) sebagian besar responden menilai capability level berada pada tingkat 5 . 


\subsubsection{Process Atrribut level}

Pada tahapan ini akan dilakukan pemberian level pada masing domain yang telah dipilih. Proses level atribut bertujuan untuk menunjukkan hasil nilai dan proses level atribut dari survei yang telah diisi oleh para responden. Setelah melakukan proses level atribut, langkah selanjutnya adalah memberikan rekomendasi, gap, dan temuan. Tingkat Kapabilitas APO08 Manage Relationship (Mengelola Hubungan).

Tabel 2 Tingkat Kapabilitas APO08

\begin{tabular}{|c|c|c|c|c|c|}
\hline \multirow{2}{*}{ No } & \multirow{2}{*}{ Sub Proses } & \multicolumn{2}{|c|}{ Nilai Kapabilitas } & \multicolumn{2}{c|}{ Tingkat Kapabilitas } \\
\cline { 3 - 6 } & & As is & To be & As is & To be \\
\hline 1 & APO08.01 & 3,32 & 4,96 & 3 & 5 \\
\hline 2 & APO08.02 & 2,44 & 3,80 & 2 & 4 \\
\hline 3 & APO08.03 & 2,52 & 3,32 & 3 & 3 \\
\hline 4 & APO08.04 & 1,92 & 2,84 & 2 & 3 \\
\hline 5 & APO08.05 & 1,44 & 2,08 & 1 & 2 \\
\hline \multicolumn{2}{|c|}{ Rata - Rata } & 2,32 & 3,4 & 2 & 3 \\
\hline
\end{tabular}

Dari tabel di atas dapat disimpulkan bahwa pada proses ensure resource optimization di Dinas Perindustrian dan Perdagangan Provinsi Sumatera Utara untuk Kondisi Sekarang (as is) memperoleh nilai 2,32 atau bisa dikatakan berada di tingkat kapabilitas level 2 yaitu Managed Process, artinya pada proses APO08 (Manage Relationship) telah adanya pengelolaan pada optimasi sumber daya yang mencakup perencanaan, pengawasan dan penyesuaian pada pelaksanaan proses.

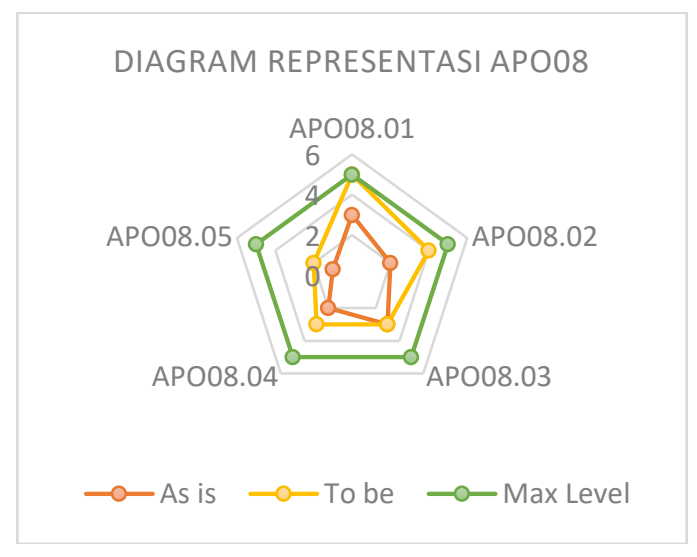

Gambar 1 Diagram Representasi APO08
Sedangkan, pada Kondisi Yang Diinginkan(to be) pada proses ensure resource optimization telah memperoleh nilai 3,4 dengan tingkat kapabilitas level 3, di mana tahap ini harus diterapakan Established Process, artinya proses APO08 (Manage Relationship) diharapkan terdapat adanya implementasi penggunaan proses yang sudah didefenisikan dan dicapainya hasil dari tujuan yang diharapkan.

\subsubsection{Pencapaian Proses Pada Dinas \\ Perindustrian dan Perdagangan Provinsi Sumatra Utara}

Langkah selanjutnya yaitu setelah menemukan tingkat kapabilitas pada setiap domain proses adalah mengecek tahapan indikator kapabilitas proses yang harus diraih oleh Dinas Perindustrian dan Perdagangan Provinsi Sumatera Utara. Pada perhitungan menggunakan skala linkert didapatkan tingkat kapabilitas pada setai proses yaitu APO08 (Manage Relationship) saat ini berada pada level 2. Sehingga jika tingkat kapabilitas APO08 berada pada level 2, maka harus memenuhi capaian process attribute dari level 1 sampai 2. Hasil Pencapaian Level APO08 (Manage Relationship).

Tabel 3 Hasil Pencapaian Level APO08

\begin{tabular}{|c|c|c|c|c|c|c|c|c|c|c|}
\hline Nama Proses & Level 0 & Level 1 & \multicolumn{2}{|c|}{ Level 2 } & \multicolumn{2}{|c|}{ Level 3 } & \multicolumn{2}{|c|}{ Level 4 } & \multicolumn{2}{|c|}{ Level 5 } \\
\hline APO08 & & PA & PA & PA & PA & PA & PA & PA & PA & PA \\
& & 1.1 & 2.1 & 2.2 & 3.1 & 3.2 & 4.1 & 4.2 & 5.1 & 5.2 \\
\hline $\begin{array}{c}\text { Peringkat berdasarkan } \\
\text { kriteria }\end{array}$ & & L & $\begin{array}{c}\text { F } \\
88,33\end{array}$ & L & & & & & & \\
$\begin{array}{c}\text { Tingkat Kemampuan } \\
\text { Tercapat }\end{array}$ & & 1 & 2 & 2 & & & & & & \\
\hline
\end{tabular}


Legenda :

$\mathrm{N}$ (Not Achieved, 0-15\%)

$\mathrm{P}$ (Partially Achieved, $>15 \%-50 \%)$

$\mathrm{L}$ (Largely Achieved, $>50 \%-85 \%$ )

F (Fully Achieved, $>85 \%-100 \%$ )

Berdasarkan penjelasan pada tabel di atas, dapat disimpulkan bahwa proses atribut 1.1 process performances mendapatkan nilai hasil pencapaian sebesar $88,88 \%$. Hal ini berarti pada proses atribut 1.1 process performances termasuk dalam kategori fully archieved (tercapai penuh) yang diartikan bahwa organisasi tersebut telah memenuhi syarat untuk pencapain level 1. Di mana sudah terdapat incident report yang menjelaskan segala kejadian pada proses hubungan dengan pelanggan atau pihak yang bekerja sama. Pada proses atribut 2.1 performance management dan proses atribut 2.2. work product management didapatkan nilai sebanyak $81,67 \%$. Hal ini berarti proses atribut 2.1 . performance management dan proses atribut 2.2 work product management termasuk dalam category largely achived (secara garis besar tercapai). Sehingga proses yang dinilai tidak dapat melanjutkan level selanjutnya atau level 3, karena syarat yang dibutuhkan untuk bisa melanjutkan proses penilaian ke level berikutnya adalah level 2 sudah masuk ke dalam kategori fully achieved (tercapai penuh).

\subsection{Analisis Kesenjangan}

\subsubsection{Reporting The Result}

Temuan, Gap dan Rekomendasi APO08 (Manage Relationship) menurut perhitungan penilaian yang telah dilakukan pada tahap data validation, untuk Kondisi Sekarang (as is), hal ini dapat di artikan bahwa pada proses APO08 saat ini berada pada level 3. Berikut tabel di bawah ini akan menjelaskan temuan, gap, dan rekomendasi dijadikan solusi pada setiap sub domain yang ada pada proses APO08.

Tabel 4 Temuan gap, dan rekomendasi APO08.01 Dan APO08.02

\begin{tabular}{|c|c|c|c|c|}
\hline Proses & $\begin{array}{c}\text { Tingkat } \\
\text { Nilai } \\
\text { Kapabilitas }\end{array}$ & Temuan & GAP & Rekomendasi \\
\hline $\begin{array}{c}\text { "APO08.01 - } \\
\text { Memahami } \\
\text { Harapan } \\
\text { Bisnis" }\end{array}$ & $3=3,32$ & $\begin{array}{l}\text { Adanya siklus untuk } \\
\text { tetap memperhatikan } \\
\text { pentingnya siklus } \\
\text { bisnis bermacam- } \\
\text { macam ke unit } \\
\text { khusus di dalam } \\
\text { organisasi, sama } \\
\text { seperti memahami } \\
\text { contoh permintaan } \\
\text { jaringan }\end{array}$ & $\begin{array}{l}\text { Divisi IT Dinas } \\
\text { Perindustrian dan } \\
\text { Perdagangan Provinsi } \\
\text { Sumatera Utara belum } \\
\text { membuat catatan } \\
\text { presentasi untuk } \\
\text { menentukan posisi Ti } \\
\text { yang dapat } \\
\text { dimanfaatkan sebagai } \\
\text { peluang dan } \\
\text { merupakan bantuan } \\
\text { utama bagi organisasi. }\end{array}$ & $\begin{array}{l}\text { Mengorganisir dan } \\
\text { membagikan aset } \\
\text { untuk dipikirkan } \\
\text { tentang kesesuaian, } \\
\text { produktivitas, } \\
\text { kelangsungan hidup } \\
\text { dan kerahasiaan } \\
\text { dalam menyelesaikan } \\
\text { semua latihan } \\
\text { organisasi. }\end{array}$ \\
\hline $\begin{array}{c}\text { “APO08.02 } \\
\text { Identifikasi } \\
\text { Peluang, } \\
\text { Resiko, dan } \\
\text { Kendala Bagi } \\
\text { TI Untuk } \\
\text { Meningkatkan } \\
\text { Bisnis" }\end{array}$ & $4=2,44$ & $\begin{array}{l}\text { Adanya ukuran } \\
\text { pekerjaan proaktif } \\
\text { dalam berbicara } \\
\text { dengan mitra utama } \\
\text { terkait peluang, } \\
\text { bahaya, dan batasan } \\
\text { yang dapat muncul } \\
\text { dengan permintaan } \\
\text { inovatif yang } \\
\text { disesuaikan dengan } \\
\text { ukuran bisnis. }\end{array}$ & $\begin{array}{l}\text { Divisi koleksi di } \\
\text { Dinas Perindustrian } \\
\text { dan Perdagangan } \\
\text { Provinsi Sumatera } \\
\text { Utara belum } \\
\text { melengkapi grafik } \\
\text { RACI untuk } \\
\text { korespondensi terkait } \\
\text { permintaan klien }\end{array}$ & $\begin{array}{l}\text { Mencirikan } \\
\text { perkembangan baru } \\
\text { secara detail, } \\
\text { (misalnya, pembagian } \\
\text { usaha dengan } \\
\text { perwakilan untuk } \\
\text { membentuk } \\
\text { kelompok unik untuk } \\
\text { menyelesaikan } \\
\text { kemajuan ini } \\
\text { sehingga pekerja } \\
\text { dapat fokus dalam } \\
\text { mengidentifikasi }\end{array}$ \\
\hline
\end{tabular}


Tabel 5 Temuan gap, dan rekomendasi APO08.03, APO08.04 Dan APO08.05

\begin{tabular}{|c|c|c|c|c|}
\hline Proses & $\begin{array}{c}\text { Tingkat } \\
\text { Nilai } \\
\text { Kapabilitas }\end{array}$ & Temuan & GAP & Rekomendasi \\
\hline $\begin{array}{c}\text { "APO08.03 - } \\
\text { Hubungan } \\
\text { Bisnis" }\end{array}$ & $3=2,52$ & $\begin{array}{l}\text { Divisi koleksi } \\
\text { memiliki opsi } \\
\text { untuk mengawasi } \\
\text { koneksi secara } \\
\text { formal dan lugas } \\
\text { dengan } \\
\text { korespondensi } \\
\text { melalui pertemuan } \\
\text { dengan unit khusus } \\
\text { yang berbeda. }\end{array}$ & $\begin{array}{l}\text { Divisi koleksi Dinas } \\
\text { Perindustrian dan } \\
\text { Perdagangan } \\
\text { Provinsi Sumatera } \\
\text { Utara belum } \\
\text { memiliki } \\
\text { dokumentasi tentang } \\
\text { pembeda bahaya } \\
\text { yang akan muncul } \\
\text { dalam mengawasi } \\
\text { asosiasi bisnis } \\
\text { dengan mitra. }\end{array}$ & $\begin{array}{l}\text { Membedakan semua } \\
\text { presentasi dari } \\
\text { organisasi yang } \\
\text { bekerja sama dengan } \\
\text { mitra, hal ini agar } \\
\text { penilaian terhadap } \\
\text { pameran kerja mitra } \\
\text { dalam kerja sama } \\
\text { dengan organisasi } \\
\text { dapat diselesaikan, } \\
\text { sehingga fungsi } \\
\text { pelaksanaan mitra } \\
\text { akan dilakukan setiap } \\
\text { bulan. }\end{array}$ \\
\hline $\begin{array}{c}\text { "APO08.04 } \\
\text { Koordinasi dan } \\
\text { Berkomunikasi"” }\end{array}$ & $3=1,92$ & $\begin{array}{l}\text { Setiap organisasi } \\
\text { yang terjadi di } \\
\text { segmen bermacam- } \\
\text { macam telah } \\
\text { disusun dan } \\
\text { dibagikan, dan } \\
\text { mengadakan } \\
\text { pertemuan sebagai } \\
\text { bertanggung jawab } \\
\text { atas perubahan ini. }\end{array}$ & $\begin{array}{l}\text { Divisi koleksi di } \\
\text { Dinas Perindustrian } \\
\text { dan Perdagangan } \\
\text { Provinsi Sumatera } \\
\text { Utara belum } \\
\text { mengarsipkan siklus } \\
\text { korespondensi } \\
\text { pengurus dengan } \\
\text { rekan kerja dan } \\
\text { siklus administrasi } \\
\text { untuk pengecekan } \\
\text { dan perincian } \\
\text { konsekuensi } \\
\text { koordinasi dengan } \\
\text { rekan kerja. }\end{array}$ & $\begin{array}{l}\text { Terdapat SOP yang } \\
\text { mengatur koordinasi } \\
\text { mitra, sehingga } \\
\text { organisasi telah } \\
\text { menyusun pedoman } \\
\text { untuk setiap } \\
\text { hubungan yang ada } \\
\text { dengan mitra. }\end{array}$ \\
\hline $\begin{array}{c}\text { “APO08.05 } \\
\text { Memberikan } \\
\text { Masukan Untuk } \\
\text { Peningkatan } \\
\text { Layanan Yang } \\
\text { Berkelanjutan" }\end{array}$ & $3=1,44$ & $\begin{array}{l}\text { Pada bagian } \\
\text { koleksi sudah } \\
\text { dilakukan siklus ID } \\
\text { loyalitas konsumen } \\
\text { dengan sifat } \\
\text { pelaksanaan } \\
\text { administrasi di } \\
\text { bidang kewenangan } \\
\text { telah dilakukan } \\
\text { dalam } \\
\text { melaksanakan } \\
\text { kewajibannya. }\end{array}$ & $\begin{array}{l}\text { Dinas Perindustrian } \\
\text { dan Perdagangan } \\
\text { Provinsi Sumatera } \\
\text { Utara belum } \\
\text { melakukan upaya } \\
\text { penawaran } \\
\text { penghargaan kepada } \\
\text { klien untuk } \\
\text { membangun } \\
\text { loyalitas konsumen } \\
\text { kepada organisasi. }\end{array}$ & $\begin{array}{l}\text { Buat latihan tertentu } \\
\text { untuk memasukkan } \\
\text { manfaat organisasi } \\
\text { dengan membuat } \\
\text { tugas bersama dengan } \\
\text { organisasi yang } \\
\text { berbeda. }\end{array}$ \\
\hline
\end{tabular}

\section{Kesimpulan}

Kesimpulan yang dapat diambil adalah bahwa Proses APO08 (Manage Relationship) di Dinas Perindustrian dan Perdagangan Provinsi Sumatera Utara terdapat adanya implementasi menggunakan proses yang sudah didefenisikan dan dapat meraih hasil dari tujuan yang diharapkan. Pada Domain APO08 (Manage Relationship) didapatkan nilai kapabilitas sebesar 2,32 untuk keadaan as is (keadaan saat ini). Hal ini dapat diartikan bahwa APO08 (Manage Relationship) berada pada tingkat 2 yang berarti pada umumnya proses yang telah dikelola secara berkala termasuk didalamnya kegiatan sudah adanya pengelolaan pada optimasi sumber daya yang mencakup 
perencanaan, pengawasan dan penyesuaian pada pelaksanaan proses.

Sedangkan untuk keadaan to be (keadaan yang diharapkan) didapatkan nilai kapabilitas sebesar 3,4. Di mana diartikan bahwa domain APO08 (Manage Relationship dapat mencapai nilai kapabilitas 3, yang berarti proses yang telah diimplementasikan ke dalam proses yang telah didefenisikan dan dapat mencapai hasil dari tujuan yang diharapkan pada target sebelumnya. Antara rentang tingkat kapabilitas 2 dengan rentang tingkat kapabilitas 3 pada APO08 terdapat nilai gap sebesar 1,08. Hal ini berarti di Dinas Perindustrian dan Perdagangan Provinsi Sumatera Utara harus memenuhi syarat indikator kapabilitas proses pada level 2 yang belum terpenuhi seperti membuat dokumentasi mengenai pengelolaan hubungan antara bisnis dengan TI, membuat SOP yang berisi mengatur koordinasi antar pihak, membuat acara yang dapat membuat saling berhubungan antara dinas dan pihak lainnya.

\section{Daftar Pustaka}

Almeida, R., Pinto, P. L., \& Da Silva, M. M. (2016). Using archimate to assess COBIT 5 and ITIL implementations. International Conference on Information Systems Development, ISD 2016, 25th, 235-246.

Bartens, Y., de Haes, S., Lamoen, Y., Schulte, F., \& Voss, S. (2015). On the Way to a Minimum Baseline in IT Governance : Using Expert Views for Selective Implementation of COBIT 5 On the Way to a Minimum Baseline in IT Governance: Using Expert Views for Selective Implementation of COBIT 5. In 2015 48th Hawaii International Conference on System Sciences, 4554-4563. IEEE. https://doi.org/10.1109/HICSS.2015.543

Basil, G. M., Agitha, N., \& Albar, M. A. (2019). Analisis Tata Kelola Teknologi Informasi Untuk Meningkatkan Mutu Sumber Daya Manusia Menggunakan Framework COBIT 5 (Studi Kasus: Politeknik Pariwisata Negeri Lombok). Jurnal Teknologi Informasi, Komputer, Dan Aplikasinya (JTIKA l(2), 245-256. https://doi.org/10.29303/jtika.v1i2.57

Devos, J., \& Van De Ginste, K. (2015). Towards a theoretical foundation of IT governance: the COBIT 5 case. Electronic Journal of Information System Evaluation, 18(2), 95-103.

Gantman, S., \& Fedorowicz, J. (2016). International Journal of Accounting Information Systems Communication and control in outsourced IS development projects: Mapping to COBIT domains. International Journal of Accounting Information Systems, 21, 63-83. https://doi.org/10.1016/j.accinf.2016.05.001

ISACA. (2012a). COBIT 5: Enabling processes. USA:
Governance Institute.

ISACA. (2012b). Process Assesment Model (PAM): Using COBIT 5. USA: IT Governance Institute.

Sa'diyah, U., \& Manuputty, A. D. (2018). Analisa tata kelola E-Government Pemerintah Kota Salatiga menggunakan Framework COBIT 5 Domain APO. Seminar Nasional Teknologi Informasi Dan Komunikasi, 2018(Sentika), 147-155.

Surendo, K. (2019). Implementasi Tata Kelola Teknologi Informasi. Bandung: Informatika.

Wolden, M., Valverde, R., \& Talla, M. (2015). The effectiveness of COBIT 5 information security framework for reducing cyber attacks on supply chain management system. IFAC-PapersOnLine, 28(3), $1846-1852$. https://doi.org/10.1016/j.ifacol.2015.06.355 